\title{
ON CERTAIN CASES OF ACUTE TREMOR OCCURRING IN CHILDREN.
}

\author{
BY REGINALD MILLER, M.D.LOND., M.R.C.P. \\ Ploysician to Out-Patients, Paddington Groen Children's Hospital: \\ Medical Registrar to St. Mary's Hospital.
}

Having no pathological evidence to bring forward as to the nature of these cases, they have been described in the title in strictly clinical terms, the phrase "acute tremor" being used for the sake of brevity and to enforce the analogy between this condition and that named by Leyden "acute ataxia" (now attributed to encephalitis cerebelli). This latter consideration is not unimportant; for I believe, for reasons to be given later, that the cases here detailed are examples of encephalitis of the mid-brain and its connections.

The tremor which, with its acute onset, is characteristic of these cases, corresponds exactly with that described by Gordon Holmes (2) as associated with destructive lesions occurring in the cerebello-rubrospinal system. It is a slow, regular tremor which at its worst is continuous except during sleep, although increased by voluntary movement, and which when less severe shows itself only on voluntary movement, or during periods of excitement. It may be universal in the head, tongue, and muscles of the trunk, abdomen, and limbs, and it is sometimes more definite in the proximal than in the peripheral parts of the extremities. In some of these cases the appearance of the child is very like that of one shivering all over from cold. In rate, the tremor is about five oscillations per second. Combined with the tremor is hypertonus, giving to the limbs some degree of uselessness, and rendering their movement slow, stiff, awkward, and this in the absence of true spasticity. There is little or no loss of power. In addition, there may be other signs present from the involvement of the parts of the brain in the immediate neighbourhood of the cerebello-rubro-spinal system, or from the presence of other foci of disease elsewhere in the central nervous system.

The important points, therefore, in these cases are three in number, the acute onset, the tremor and the hypertonus, the last two differentiating the condition from cerebellar encephalitis in which ataxia and 
hypotonus are found, with the possible additions of nystagmus and scanning speech.

Where these cases have been reported, as by Batten [2], they have been grouped as cases of cerebellar encephalitis, but it would appear that they warrant separation from these, a view which I put forward in a paper concerning encephalitis [3], and which is also held by Poynton [4] in a communication in which two such cases are described, one of which is Case 3 of this series.

The cerebello-rubro-spinal system consists of two parts-the cerebello-rubral and the rubro-spinal. In the former the dentate nucleus of the cerebellum is connected with the red nucleas and optic thalamus of the opposite side by the superior cerebellar peduncle; in the latter the red nucleus is connected by the tractus rubro-spinalis (Monakow's bundle) with the opposite side of the spinal cord. In the pons Monakow's bundle passes close to the nucleus of origin of the seventh cranial nerve. In this system, therefore, are two decussations, each of which occurs in the immediate neighbourhood of the red nucleus, the superior cerebellar peduncles crossing before entering the nucleus, and Monakow's bundles crossing after leaving it. From this it follows that if the tremor be due to destruction of any part of the system, the movement will be on the same side as the lesion, unless the red nucleus itself or its immediate surroundings be involved, in which case it will be on the opposite side.

It will be convenient now to give an account of the clinical histories of the cases, but before doing so I must express my indebtedness to Dr. Voelcker, Dr. Colman, and Dr. Poynton for permission to use the patients I watched when Medical Registrar to the Hospital for Sick Children, Great Ormond Street. My thanks are also due to the Casualty Medical Officer of that hospital, Dr. L. G. Parsons, for his kindness in allowing me to see the last patient here reported, which was brought up to his department.

\section{Case 1.}

C. A. P., a boy, aged $2 \frac{1}{2}$.

History of illness.-In the first week of October, 1906, the child, when seated at table, was noticed to go suddenly "all of a heap," with his mouth drawn to the left. He was unconscious, and remained so for three weeks, although he was very irritable when disturbed. His limbs were observed to tremble. After three weeks he regained consciousuess and was found to have lost his speech. He lay helpless in bed, with the shaking movements continuing all the time except during sleep. He was admitted to the Hospital for Sick Children, under Dr. Colman, on November 12, 1906. 
Past history. - Had always been a very healthy child, and had lenrned to walk and talk well.

Family history.-The patient was the elder of two children; the other: is well. The mother had no miscarringes and there was nothing of importance in the family history.

On admission (November 12).-The child was very well nourished, showing only slight bony signs of rickets. Apart from the nervous system no abnormalities were present.

Mentally the child was very irritable, although probably not in pain, and was extremely emotional. He cried very loudly, and would change from this into laughter, which was excessive and hysterical, resembling that of a child heing tickled. He made no intelligible efforts to speak, but apprecinted noises and things to ent. No diminution of emotional expression could be detected.

Tremor was seen in the head, tongue, trunk, and all four limbs. It was present except during sleep, but it was increased on voluntary movement. In the limbs it was more marked in the proximal than in the distal parts. In the hands it was a slow rhythmic tremor of about five per second. The whole appearnnce of the child was like one shivering from cold. In addition the voluntary movement of the limbs was performed slowly and stiffly as in a case of paralysis agitans. On the right side there was possibly some spastic rigidity.

Examination of the cranial nerves showed that there was some affection of the sixth and seventh nerves on the right side. The others appeared normal. The optic dises and the tympanic membranes were normal.

The reflexes showed little change. The right abdominal reflexes were absent, the left being just obtainsble. The pupil, corneal and palate reflexes were normal. The tendon reflexes were brisk and equal on the two sides, and the plantar responses flexor. The jaw-jerk was nctive. There was reflex incontinence of urine.

Concrse of disease.-The child was seen at intervals for eighteen months. During the first weeks the evening temperuture was slightly raised, us is seen in recent cases of acute poliomyelitis. A month after admission the crinain nerves and the abdominal reflexes had become normal and the tremor less marked, so that it was present only on voluntary movement. The hypertonus was still evident. A month later be was able to walk a little.

During the rest of the time slight further improvement took pluce. By March, 1908, all signs of the tremor had disappeared, but the movements of the limbs and of the head were slow and stiff. He was able to walk very fairly well by this time. Mentally he had made practically no improvement at all. He was a little quieter, but quite idiotic. He still laughed and cried hysterically, was extremely greedy, dirty in his habits, and made no intelligible effort to talk.

In February, 1908, he had three generalized convulsions which were not followed by any observable deterioration. In May, eighteen months after the 
onset of the illness, he had a severe fit which proved fatrl. No post-mortem examination was possible.

Localization.-From the affection of the sixth and seventh nerves on the right side, the general tremor and great emotionalism, we may surmise that the lesion was an extensive one involving the mid-brain and pons. But in addition it may well be that the cerebral cortex sustained some damage, which view may be supported by the prolonged unconsciousness at the time of the onset, the profound mental change, and the later development of epilepsy.

(This patient was shown by the writer as a case of encephalitis, chiefly affecting the mid-brain, at the Clinical Society, April, 1907.)

\section{CASE 2.}

L. S., a girl, aged $5 \frac{1}{4}$.

History of illness.-On August 3, 1907 she complained of pains in the back and limbs and could not put the heel of the left foot to the ground. On the next day "shivering" of the right hand was noticed and she was unable to walk. She had no apparent feverishness, no convulsions, but talked in her sleep at night and seemed drowsy. She was kept in bed for a week. Only slight improvement was made until she was admitted to the Hospital for Sick Children on August 20, under the care of Dr. Colman.

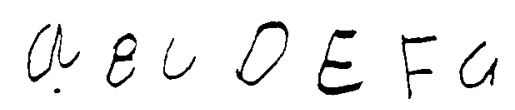

A Speoimen of the Handwriting of L. S., agod 6 t yanrs, 16 months after onset of illness (Cuse 2).

Past history.-Had always been a big, strong child. Had measles five months ago and whooping-cough previously.

Family history.-Only child; the mother had had no miscarriages. Both paternal grandparents died of consumption. Maternal grandmother and uncle died insane at the ages of 62 and 29 years respectively. Parents healthy.

On admission (August 20, 1907). - The child was woll developed and nourished. She was irritable and cried when disturbed; her memory and speech were good. When sitting up the head tended to assume the corebellar attitude, the right oar approximating to the right shoulder and the face turning to the left with the chin raised. There was slight lateral nystagmus to right and left, none vertically. The gait was very ataxic and the child could not walk alone, falling backwards. The left limbs showed ataxic movements in both arm and leg. On the right side there wrs no ataxia, but tremor and hypertonus, the tremor being of the intention type and the voluntary movements of the limbs being slow and stiff. The cranial nerves vere normal and the deep reflexes brisk, but rather less so in the left than in the right limbs. There was no evidence of involvement of either pyramidal tract.

Course of illness.-Very rapid improvement took place. The child quickly 
became docile and quiet. Within a week the ataxy and the tremor diminished considerably, and within a fortnight she could walk unaided. A month later she could walk and run well, but some little ataxia showed itself in the left leg when she tried to kick a ball on the ground with the left foot. By this time the tremor had quite gone from the right leg, but was still just recoguizable in the right hand.

In December, 1908, sixteen months after the onset of the illness, the child still showed.a very slight tremor in the right hand when trying to do any fine action with her arm unsupported, but she was able to foed herself perfectly well. A specimen of her handwriting at this date shows how very slight was the tremor with her arm supported. The movement is at its worst when she is wakened from sleep, or when she is nervous. Mentally she was perfectly normal, and she appenred very strong and healthy in every other respect.

Localization.-From the presence of the ataxia on the left side, the cerebellar tilt of the head and the slight nystagmus, it may be supposed that the lesion was in the cerebellum, and that the tremor on the right side was due to the involvement of the right dentate nucleus.

\section{CASE 3.}

A. C., a girl, aged 13 months.

History of illness. - The mother stated that the child had been seized with convulsions five weeks previously (i.e., the beginning of August, 1908), and that these had continued occurring several times a day. After four weeks the child seemed slightly better for two days, but then relapsed, being convulsed and unconscious. Something wrong with the eye had been noticed for the lust month. There had been no gastro-intestinal disturbance.

The mother was an Italian and could speak but little English, and I think that the history given may be correctly interpreted thus: that the child was seized suddenly with an illness in which movements of the limbs were present, and that for the first week the child was unconscious or very drowsy, and as this condition passed off the squint was noticed for the first time. This view of the history is supported by the fact that the child when first seen was neither convulsed nor unconscious, as the mother had stated. She was admitted to Dr. Voelcker's ward at the Hospital for Sick Children, under the care of Dr. Poynton.

Past and family history.- Nothing was noted on these points except that the parents had had no fits.

On admission (September 7, 1908).-The patient was a very fat child, showing rickety changes of the head and chest. She was conscious and was not irritable. The pupils were small, rencted poorly to light, especially on the right side, but dilated well under atropine. There was complete paralysis of the right extermal rectus, and there was definite wenkness of the right side of the face, the eye not closing completely on this side. There was some doubtful weakness of the left external rectus. 
The tremor was constantly present, except during sleep, in the head, trunk and limbs, being most definite in the lower extremities and least definite in the head. It was increased by voluntary movement and was in every other way similar to the rhythmic movements described in the other cases. It was very difficult to say that there was any definite hypertonus of the limbs. There was no loss of motor power. The reflexes were unaltered; the abdominal reflexes were all present, the knee-jerks brisk and equal, and there was no ankle-clonus. On attempting to elicit the plantar responses, voluntery movements of flexion were obtained. Lumbar puncture was performed on September 9, and clear fluid was obtained, which was sterile and showed no deposit or clot, and in which no cells or organisms were found.

Course of illness.-During the next week there was a good deal of improvement, the tremor becoming less and showing only on voluntary movement.

Localization.-From the affection of the sixth and seventh cranial nerves on the right side, the lesion, or part of it, may be thought to be pontine.

\section{CASE 4.}

D. K., a girl, aged $2 \frac{9}{4}$.

History of illness.-On October 24, 1908, the child suddeuly became very drowsy and passed rapidly into an unconscious condition. There was no convulsion. She remained unconscious for four days. The tongue was noticed to tremble from the first day of the disease, but no tremor was seen in the limbs until the child sat up towards the end of the first week, when it was observed in the head and left limbs when voluntary action was undertaken. The movement was described as giving an appearance of "shivering." The squint and facial wenkness were not noted. Rapid improvement had occurred. She had become greedy and was very noisy at night. During the last week she has begun to try to talk again.

Pcust history.-Physically well, but was described as being backward in her talking and always passionate and "spoilt." Habits not clean. Was said to have had convulsions at birth and at 6 weeks of age; no fits since then.

November 10, 1908.-Was seen as an out-patient at Paddington Groen Children's Hospital seventeen days after the onset of the illness. She was found to be a strong, well-developed child. She was extremely passionate and irritable, and cried very loudly under examination; but there was no hysterical laughter, as in Case 1. There was weakness of the left external rectus and of the left frcial muscles, the eyelids not being well closed on this side. Slight tremor was seen in the tongue, in the left arm and leg. In the limbs it was only present during volitional movement. Owing to the tremor in the legs she could not stand, but there was no actual loss of motor power in the limbs. The voluntary movements of the affected limbs were slowly and stiffy performed. So far as could be made out, the reflexes were unaltered; it was impossible to test the abdominal reflexes owing to the child's behaviour.

Course of illness. - When seen a fortnight later she was much more docile. 
The cranial nerves and the left arm were normal, but the left leg showed slight tremor still, although she was beginning to walk alone. The abdominal reflexes were normal.

Within six weeks of the onset of the diserse the child appeared to be perfectly well, walking, sleeping, and behaving well. She was said to be using more words than before her illness.

Localization.-It is probable that in this case there was a small lesion involving the sixth and serenth cranial nerves and the rubro-spinal (Monakow's) tract in the left side of the pons.

\section{CASE 5.}

W. W., a boy, aged $1 \frac{3}{4}$.

History of illness. - At the end of July, 1908, he suddenly began to scream violently, and appeared frightened, holding on to a chair. He was pacified after a few minutes, and as he got very drowsy he was put to bed. The next day continuous trembling was noticed in all the limbs. From this time he was unable to walk, be lost the few words be had learned, and became very noisy, nervous, and greedy. The trembling continued, but becrme gradually less.

Past 7istary.- Was a strong child, good tempered, able to walk, and was beginning to talk before his illness. No other diseases.

Family history.--The child's mother had always been very nervous and "hysterical," and had lately developed epilepsy. She had had no miscarringes. Father strong. One other child, aged 8, well.

November 23, 1908. - When first seen, four months after the onset of the disease, he was found to be a strongly-built child, and very fat. He was very noisy, crying and laughing hysterically. He could not talk at all, and was mentally deficient and greedy. The tremor was seen in the limbs, showing only on voluntary movement; in the legs it was sufficient to prevent his standing. The movement of the limbs was slow and stiff in charncter. There was some jerky movement of the head and eyes, but no tremor or nystagmus. The cranial nerves and the reflexes were normal.

Course of illness.- A fortnight later he was a little quieter in his behaviour; the tremor was less, and the child was beginning to stand with assistance. There was no mental improvement. There had been no fits.

Localization.-Part of the lesion may be supposed to be in the mid-brain, involving the red nuclei.

\section{CASE 6.}

A. Q., a boy, aged 15 months.

History of illness.-On October 19, 1908, the boy was put to bed well, and, although he slept with his mother, nothing was noticed until the morning, when he was found to be very drowsy and to be "shivering" all over, but the limbs were not paralysed. No fits were seen, nor was the boy unconscious. The movements very rapidly got better, but the child was not able to walk for about a 
fortnight on rccount of the trembling of the legs. A week after the onset of the illness the right arm became useless, and hung down by the side. This paralysis was not accompanied by any constitutional symptoms, and was first noticed one morning after the child had had a normal night's rest.

Past history.-Had always been a fairly strong child, but was subject to attacks of vomiting. Had no previous ilnesses except these bilious attacks.

Family history.-Only child. No neuropathic inheritance could be traced. No cases of infantile paralysis were known of in the neighbourhood.

January 29, 1909.-When first seen he was found to be a strong, fat boy, showing no trace of the tremor described by the mother. He was able to walk well, and could say more words than before the illness. No mental impairment could be found. The right arm was paralysed, and hung flaccid at the shoulder. There was slight power in the fingers of the right hand. According to the mother's statement, practically no improvement had taken place in tho condition of this arm.

Localnzation.- It would appenr that a slight lesion had occurred somewhere in the cerebello-rubro-spinal system, and that there had been a relapse \& week later (the usual time for a relapse when such does occur), affecting the cervical enlargement of the cord.

\section{ETIOLOGY.}

It is necessary here to submit the clinical evidence which supports the contention that we are dealing with cases of encephalitis, using that term as indicating a disease of the brain similar to that which is known as acute poliomyelitis when it affects the spinal cord. In Case 6 we have a spinal lesion of the acute poliomyelitis type, occurring as a relapse in a child who had developed tremor a week previously. But apart fiom such evidence as this, acute poliomyelitis has certain well-marked characteristics which should be reproduced in polio-encephalitis with some modification, and these points may now be considered.

(a) The child who is attacked by poliomgelitis is very frequently the strong and fat, the delicate and thin children being notably spared. This rule held good in the six cases here reported, as it has in all other cases of encephalitis that I have seen. (b) The seasonal incidence of these cases corresponds to that of acute poliomyelitis, one being in July, two in August, and three in October. (c) The age-incidence, from 13 months to $5 \frac{1}{2}$ years, corresponds exactly to that at which the spinal disease is commonest. (d) The amount of constitutional disturbance at the onset of the disease is very variable, as in poliomyelitis, although it is natural to suppose that convulsions and unconsciousness are likely to be of more common occurrence. In Case 1 the child was taken ill with a convulsion and was said to have been unconscions for the 
following three weeks, while in Case 2 there was no fit and only slight drowsiness was observed. (e) In poliomyelitis the onset is acute and the harm done reaches a maximum within a few hours; anything like weakness becoming gradually an absolute paralysis is not seen. So, too, in these cases the disease is acute and its effects complete and absolute; bat here care must be taken in examining the clinical history of the illness, for the same difficulty is experienced as has been found in dealing with cases of cerebellar encephalitis. Should the child be drowsy or unconscious the tremor may not be seen or may be regarded as signifying a convulsion, so that one may hear that the trembling came on some days after the onset of the illness. This possibility is well instanced in Case 4, in which the mother stated that the child was unconscious for four days and when sat up was seen to have shaking of the limbs. With questioning, however, it transpired that the tongue was seen to tremble when the child was fed on the first day of the illness. $(f)$ As in poliomyelitis, the tendency of the disease is towards improvement or total recovery, while relapses are very exceptional. (g) Examination of the cerebro-spinal fluid was negative in the one case in which it was undertaken (Case 3), as it is in spinal cases.

In none of the cases here reported had the disease been preceded by one of the acute specific fevers of childhood within three months of the date of onset, a point which has been noted before in dealing with encephalitis and which by some has been used as an argument against the condition being the same disease as poliomyelitis. In my experience such a sequence in true cases of acute poliomyelitis is by no means 80 common as some have seemed to imply. ${ }^{1}$

It may be pointed out, without comment, that in the five cases in which it was possible to get a true family history two showed a strong neuropathic taint, while the third child was described as spoilt and passionate and suffered from nocturnal enuresis. I do not think that any such association has been noted in cases of acute poliomyelitis.

\section{Srmptomatologr.}

The acute onset, the tremor and hypertonus are the important characteristics of this group of cases, and have been sufficiently described above.

I In order to substantiate this point I have eramined the records of the Hospital for Sick Children for cases of acute poliomyelitis whose onset occurred in 1906 . Of these I found fifteen, and in only one was there a history of an acute specific fever within three months of the parnlysis, while eight had never had any of the exnnthemata at any time. The montbly incidence of these cases was August 5, September 6, Ootober 9, November 1. 
In addition, there may be other signs due to involvement of some part of the nervous system other than the cerebello-rubro-spinal tracts. Thus the anterior horn-cells of the spinal cord may be affected (Case 6), or the cerebellar involvement may produce ataxia (Case 2), or the sixth and seventh cranial nerves in the pons may be damaged (Cases 1,3 , and 4). Excessive emotionalism was present in Case 1, and to a less extent in Cases 4 and 5, and may perhaps be regarded as being produced by damage of the optic thalamus. Mental deterioration (Cases 1 and 5) appears to be a serious symptom, and if present may perhaps be thought to be due to an associated polio-encephalitis superior, involving. the frontal areas of the cerebrum as has been described by Batten [1]. Hemiplegia may occur, with the tremor displayed on the paralysed side, or a third nerve paralysis.

\section{Diagnosis.}

This naturally falls under two headings: the character of the lesion and its localization.

It is not maintained that all cases of acute tremor are to be regarded as due to polio-encephalitis, but only that certain of them may be placed in this group. The diagnosis can to a large extent be made by the exclusion of other possibilities, but those etiological factors already mentioned-the type and age of child, the season of the year, the character of the onset, and the course of the disease-may be of use in settling the matter. The cerebro-spinal fluid shows no abnormalities. The most likely causes, apart from polio-encephalitis, are a tuberculous tumour or a thrombosis due to syphilitic endarteritis.

Of the former I have seen one example, the tremor being seen during the first few days in a case of tuberculous meningitis, and being due to a small mass found after death in the dentate body of the cerebellum. In such a case the child, although it may recover, is generally far from well nourished and robust; there may be signs of tuberculosis elsewhere, optic neuritis may be present, and the cerebro-spinal fluid will show an excess of lymphocytes. I have seen no case in which the tremor could be said to be due to a syphilitic thrombosis; but judging by what occurs where other parts of the brain are affected, the diagnosis should be clear by the presence of signs of inherited syphilis (particularly in the eye-grounds), and the possible warning convulsions or: "fainting attacks." Here, again, lymphocytes would be present in the cerebro-spinal fluid:

The localization of the lesion has been discussed. The tremor and 
hypertonus distinguish these cases from the true cerebellar ones which show ataxia and hypotonus. The part of the cerebello-rubro-spinal system attacked is diagnosed by the accompanying signs if such are present.

\section{Prognosis.}

There is a general tendency towards improvement. In all six cases the tremor rapidly diminished, and in a few weeks or months became inappreciable. Similarly the cranial nerve paralyses disappeared. Of far more serious import is the mental deficiency, which may remain after the acute attack is over, and which, where it was present in these cases, remained unimproved. In one of these epilepsy developed and proved fatal.

\section{REFERENCES.}

1] BatTen. "Cerebral Symptome due to Encephalitis," Med. Soc. Trans., vol. xxvii, p. 116.

[2] Hocmes. "On Certain Tremors in Organic Cerebral Lesions," Brain, 1904, p. 327.

[3] Miller. "On Acute Poliomyelitis and the Allied Conditions in the Brain," St. Mary's Hosp. Gas., December, 1907.

[4] Poymton. "Some Unusual Sequelæ of Convulsive Seizures in Cbildbrod," Lancet, Ootober 31, 1908. 